\title{
Isolation and Characterization of Methanogenium aggregans sp. nov.
}

\author{
B. M. OLLIVIER, ${ }^{1}$ R. A. MAH, ${ }^{2 *}{\text { J. L. GARCIA },{ }^{1} \text { AND R. ROBINSON }}^{3}$ \\ Laboratoire de Microbiologie ORSTOM, Université de Provence, 13331 Marseille Cédex 3, France ${ }^{1}$; Division of \\ Environmental and Occupational Health Sciences, School of Public Health, University of California at Los Angeles, Los \\ Angeles, California $90024^{2}$; and Department of Microbiology and Cell Science, University of Florida,
} Gainesville, Florida $32611^{3}$

\begin{abstract}
A new mesophilic methanogenic bacterium was isolated from a sewage sludge digestor. The cells were irregular cocci (diameter, 0.5 to $2.0 \mu \mathrm{m}$ ) and occurred singly or in small aggregates. Adjacent cells did not appear to touch, even in aggregates. This bacterium was not motile and did not possess flagella. Colonies appearing after 1 week of incubation were white and $1 \mathrm{~mm}$ in diameter. Older colonies were yellow and up to $4 \mathrm{~mm}$ in diameter. The organism used $\mathrm{H}_{2}-\mathrm{CO}_{2}$ or formate as an energy source. Acetate and either yeast extract or Trypticase peptone were required for growth. The optimum pH for growth was between 6.5 and 7.0. The $\mathrm{NaCl}$ requirement for methanogenesis was less than $0.2 \mathrm{~g} / \mathrm{liter}$. The deoxyribonucleic acid base composition was $52 \mathrm{~mol} \%$ guanine plus cytosine. This isolate is named Methanogenium aggregans sp. nov., and the type strain (strain MSt) has been deposited in the Deutsche Sammlung von Mikroorganismen as strain DSM 3027.
\end{abstract}

Irregularly shaped coccoid cells occur in three genera of methanogenic organisms, Methanosarcina, Methanococcus, and Methanogenium. Most species in these genera are mesophilic methanogens isolated from marine environments $(5,10,16,18)$. Most use either $\mathrm{H}_{2}-\mathrm{CO}_{2}$ or formate for growth and methane formation. Two notable exceptions to the use of these two substrates are the species Methanosarcina mazei and "Methanosarcina acetivorans," which use methanol, acetate, and methyl-, dimethyl-, and trimethylamine. Recently, thermophilic coccoid isolates have also been reported $(6,7,9,14)$, again from marine origins. We describe here the isolation and characterization of a new species of coccoid methanogenic bacterium from a sewage sludge digestor. The name Methanogenium aggregans sp. nov. is proposed for this isolate.

\section{MATERIALS AND METHODS}

Enrichment and isolation. An enrichment culture was inoculated with a sample from a sewage sludge digestor at Bourg en Bresse, France. This enrichment culture was grown in $20 \mathrm{ml}$ of medium in a $60-\mathrm{ml}$ serum bottle with 2 atmospheres $(203 \mathrm{kPa})$ of $\mathrm{H}_{2}-\mathrm{CO}_{2}$ as the substrate. The cultures were repressurized with $\mathrm{H}_{2}-\mathrm{CO}_{2}$ as needed and transferred (2 $\mathrm{ml})$ at weekly intervals to fresh media. Cultures were incubated without shaking at $37^{\circ} \mathrm{C}$. For isolation of axenic cultures of methanogens, the enrichment culture was transferred to media containing penicillin $(3,000 \mathrm{U} / \mathrm{ml})$; after growth (as measured by methanogenesis), the enrichment culture was serially diluted and inoculated into roll tubes (8).

Culture media. The isolate was cultured on medium containing $1.0 \mathrm{~g}$ of $\mathrm{NH}_{4} \mathrm{Cl}, 0.4 \mathrm{~g}$ of $\mathrm{K}_{2} \mathrm{HPO}_{4} \cdot 3 \mathrm{H}_{2} \mathrm{O}, 0.2 \mathrm{~g}$ of $\mathrm{MgCl}_{2}, 0.5 \mathrm{~g}$ of cysteine hydrochloride, $5.0 \mathrm{~g}$ of sodium formate, $1.0 \mathrm{~g}$ of sodium acetate, $1.0 \mathrm{~g}$ of Trypticase peptone (BBL Microbiology Systems, Cockeysville, Md.), $1.0 \mathrm{~g}$ of yeast extract (Difco Laboratories, Detroit, Mich.), $0.001 \mathrm{~g}$ of resazurin, $0.3 \mathrm{~g}$ of $\mathrm{K}_{2} \mathrm{HPO}_{4}, 10 \mathrm{ml}$ of a trace minerals solution (1), $5 \mathrm{ml}$ of rumen fluid, and $1,000 \mathrm{ml}$ of deionized water. When roll tubes were used, $2.0 \%$ agar was added.

\footnotetext{
* Corresponding author.
}

The medium was adjusted to $\mathrm{pH} 7.0$ with $10 \mathrm{M} \mathrm{KOH}$, boiled under a stream of $\mathrm{O}_{2}$-free $\mathrm{N}_{2}$, and cooled to room temperature (or $50^{\circ} \mathrm{C}$ for agar medium). The medium was distributed into serum bottles $(20 \mathrm{ml}$ of medium in $60-\mathrm{ml}$ serum vials) in an anaerobic glove box (Coy Lab Products, Ann Arbor, Mich.). The bottles were stoppered with butyl rubber closures (Bellco Glass, Inc., Vineland, N.J.) and removed from the glove box. The gas atmosphere in the bottles was replaced with $\mathrm{N}_{2}-\mathrm{CO}_{2}(4: 1)$. After autoclaving $\left(121^{\circ} \mathrm{C}\right.$ for $20 \mathrm{~min}$ ), $0.4 \mathrm{ml}$ of $1.0 \% \mathrm{Na}_{2} \mathrm{~S} \cdot 9 \mathrm{H}_{2} \mathrm{O}$ and $0.3 \mathrm{ml}$ of $10 \% \mathrm{Na}_{2} \mathrm{CO}_{3}$ (sterile, anaerobic solutions) were injected into the bottles just before inoculation.

For roll tube media, $2 \%$ agar was added; $4.5-\mathrm{ml}$ portions were dispensed into Pyrex culture tubes (Bellco), which were sealed with no. 00 butyl rubber stoppers (Arthur $\mathrm{H}$. Thomas Co., Philadelphia, Pa.). Sulfide $(0.1 \mathrm{ml}$ of a $1 \%$ solution) and sodium carbonate $(0.075 \mathrm{ml}$ of a $10 \%$ solution) were added to tubes prior to inoculation.

Media at different $\mathrm{pH}$ values were prepared from bottles of dispensed medium by adding $1 \mathrm{M} \mathrm{NaOH}$ or $1 \mathrm{M} \mathrm{HCl}$ from anaerobic stock solutions.

Complex broth medium containing $0.3 \%$ glucose, $0.1 \%$ yeast extract, and $0.1 \%$ Trypticase was used to test culture purity under aerobic and anaerobic conditions.

Analytical methods. Duplicate vessels were used throughout this work, and all experiments were repeated at least twice. $\mathrm{CH}_{4}$ was measured by gas chromatography as previously described (2). Sensitivity to sodium dodecyl sulfate was determined by mixing cell suspensions with a $1 \%$ (wt/vol) sodium dodecyl sulfate solution in the required proportions. Lysis of cells was determined by phase-contrast microscopy.

Deoxyribonucleic acid base composition. The method of Price et al. (12) was used to extract and purify deoxyribonucleic acid. Buoyant density was determined by centrifugation in a $\mathrm{CsCl}$ density gradient $(11,17)$.

Gases. $\mathrm{N}_{2}-\mathrm{CO}_{2}$ (4:1) and $\mathrm{H}_{2}-\mathrm{CO}_{2}(4: 1)$ mixtures were purchased from Search Medical Products, Cucamonga, Calif.

Microscopy. Phase-contrast photomicrographs were taken with a Universal research microscope (Carl Zeiss, Oberkochen, West Germany). For thin-section electron micros- 


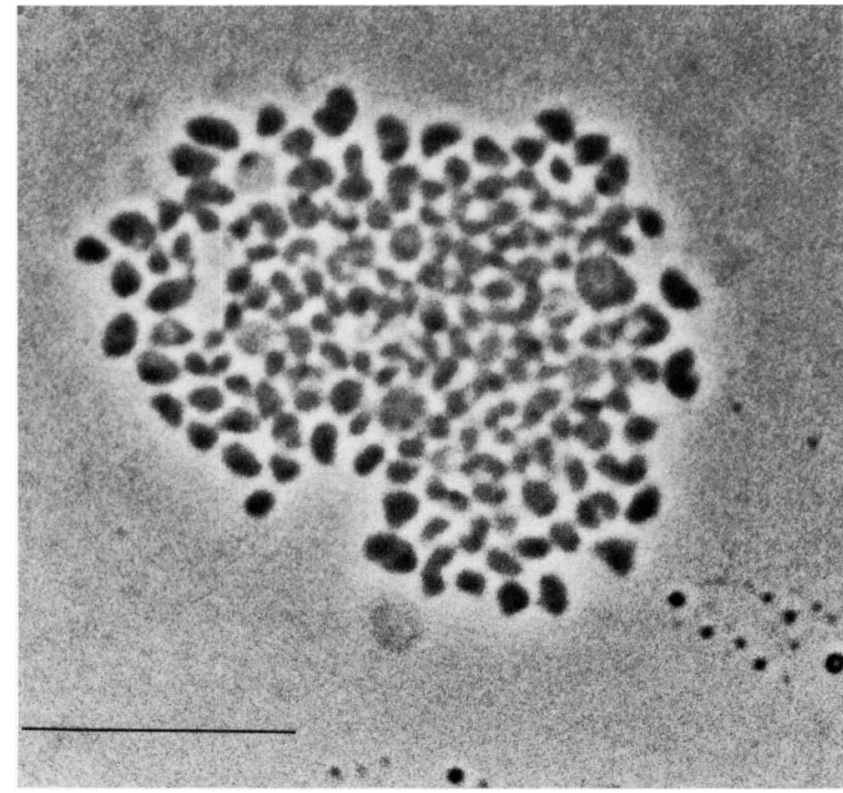

FIG. 1. Phase-contrast photomicrograph of aggregates of Methanogenium aggregans. Bar $=10 \mu \mathrm{m}$.

copy, cells were fixed with glutaraldehyde and osmium tetroxide and were then enrobed in Spurr plastic as previously described (15).

\section{RESULTS}

Isolation procedure. After 7 days, the penicillin-treated enrichment culture contained a coccoid methanogen which formed fluorescent aggregates under epifluorescent microscopy at ca. $420 \mathrm{~nm}$. The enrichment was diluted in liquid medium and inoculated into roll tubes containing $80 \mathrm{mM}$

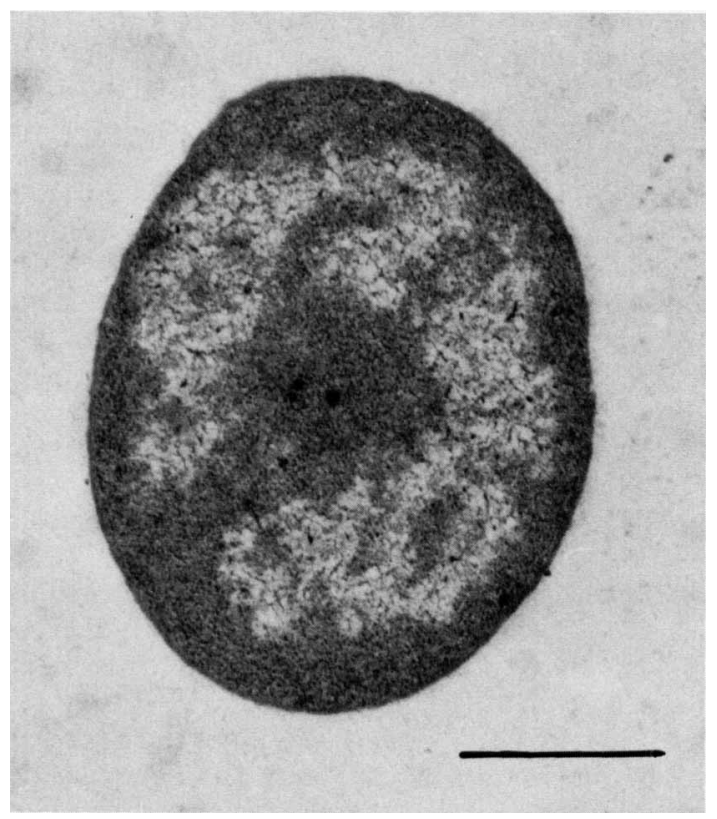

FIG. 2. Thin-section electron photomicrograph of an individual cell of Methanogenium aggregans strain $\mathrm{MSt}^{\mathrm{T}}$. Bar $=0.5 \mu \mathrm{m}$. sodium formate as the energy source. Isolated colonies in roll tubes inoculated from high dilutions were observed after 1 week of incubation at $37^{\circ} \mathrm{C}$. Colonies were successively picked and reinoculated into roll tubes until a single colony type was observed. Purity was tested by direct microscopic examination and by inoculation of the culture into complex medium.

Morphology. Young colonies (1 week) were white, round, convex, and $1 \mathrm{~mm}$ in diameter. Older colonies were yellow and as large as 3 to $4 \mathrm{~mm}$ in diameter. The cells were irregular cocci 0.5 to $2.0 \mu \mathrm{m}$ in diameter (average diameter, $1 \mu \mathrm{m}$ ) which occurred as a mixture of single cells and small compact aggregates (Fig. 1). Adjacent cells never appeared to touch, suggesting the presence of capsular material. The cells stained gram negative. The organism was nonmotile, and flagella were never observed when cells were stained by the procedure of Rhodes (13) or when cells were observed by electron microscopy. Electron photomicrographs revealed a thin cell wall (Fig. 2); the isolate was lysed in the presence of $0.03 \%$ sodium dodecyl sulfate.

Substrates for methanogenesis. The bacterium used only formate or $\mathrm{H}_{2}-\mathrm{CO}_{2}$ as an energy source. With formate as the substrate, growth was as rapid with mineral $\left(\mathrm{HCO}_{3}{ }^{-}\right)$or organic [piperazine- $N, N^{\prime}$-bis(2-ethanesulfonic acid)] buffer. Acetate, methanol, or methylamines were not growth substrates. The generation time on formate was $8 \mathrm{~h}$ at $37^{\circ} \mathrm{C}$.

Growth conditions. The isolate grew optimally in culture medium without added $\mathrm{NaCl}$ (Fig. 3). The total medium concentration of $\mathrm{Na}^{2+}$ was equivalent to less than $2 \mathrm{~g}$ of $\mathrm{NaCl}$ per liter. No growth occurred when $30 \mathrm{~g}$ of $\mathrm{NaCl}$ per $\mathrm{ml}$ was added. The optimum growth temperature was $35^{\circ} \mathrm{C}$ (Fig. 4). Methane production was slow at 25 or $40^{\circ} \mathrm{C}$. The optimum $\mathrm{pH}$ was between 6.5 and 7.0 (Fig. 5) within a growth range of $\mathrm{pH} 6.0$ to 8.0. Acetate plus either yeast extract or Trypticase peptone was required for growth; the culture medium contained $1 \mathrm{~g}$ of acetate per liter, $1 \mathrm{~g}$ of Trypticase peptone per liter, and $1 \mathrm{~g}$ of yeast extract per liter. Growth was complete within 6 days. When acetate was

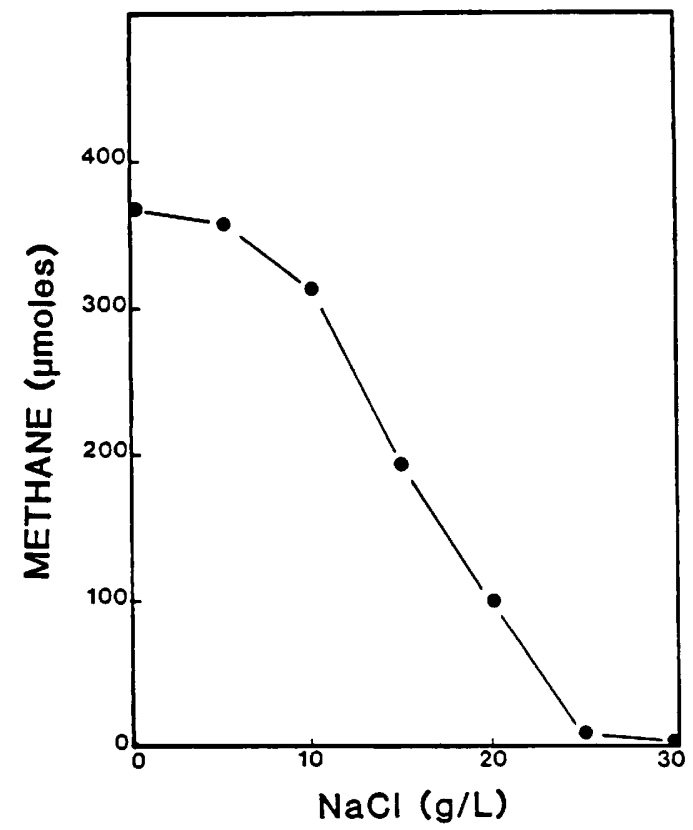

FIG. 3. Effect of $\mathrm{NaCl}$ addition on methane production by Methanogenium aggregans. Cultures were grown in $20 \mathrm{ml}$ of liquid medium for 4 days at $35^{\circ} \mathrm{C}$. 
omitted, methane production was about $2 \%$ or less of the normal amount, even after 55 days of incubation. When $1 \mathrm{~g}$ of sodium acetate per liter but neither yeast extract nor Trypticase peptone was added, methane production was about $5 \%$ of the normal amount. If acetate plus either Trypticase peptone or yeast extract was added, methane production was the same as it was with the normal medium.

Deoxyribonucleic acid base composition. The guanine-pluscytosine content was $52 \mathrm{~mol} \%$.

Indirect immunofluorescence. Conway de Macario et al. determined immunological cross-reactions (3) with 25 polyclonal antisera to representative strains of methanogens (4), including Methanogenium cariaci and Methanogenium marisnigri. Tests made with $\mathrm{S}$ probes gave no reactions with any of the antisera except a weak $(1+)$ reaction with antiserum to Methanospirillum hungatei $\mathrm{JF}^{\mathrm{T}}(\mathrm{T}=$ type strain).

\section{DISCUSSION}

Strain $\mathrm{MSt}^{\mathrm{T}}$ most closely resembled members of the order Methanomicrobiales. Its morphology indicated that it does not belong to the Methanobacteriales, and its guanine-pluscytosine content indicated that it does not belong to the Methanococcales. Within the order Methanomicrobiales there are two genera which contain coccoid bacteria, Methanosarcina and Methanogenium. Some species of Methanosarcina have morphophases of coccoid morphology, but there are metabolic characteristics universal to the species of this genus, such as use of trimethylamine or methanol as a substrate, which distinguish them from our isolate. Morphologically, strain $\mathrm{MSt}^{\mathrm{T}}$ resembled members of the genus Methanogenium. It differed from Methanogenium cariaci and Methanogenium marisnigri by its higher optimum growth temperature, its formation of aggregates, the absence of flagella, and its lack of an immunological cross-reaction with either of these Methanogenium species. Furthermore, neither of these species grows on formate in the presence of sodium bicarbonate buffer, and both require elevated levels of $\mathrm{NaCl}$. Our isolate differed from the other species of

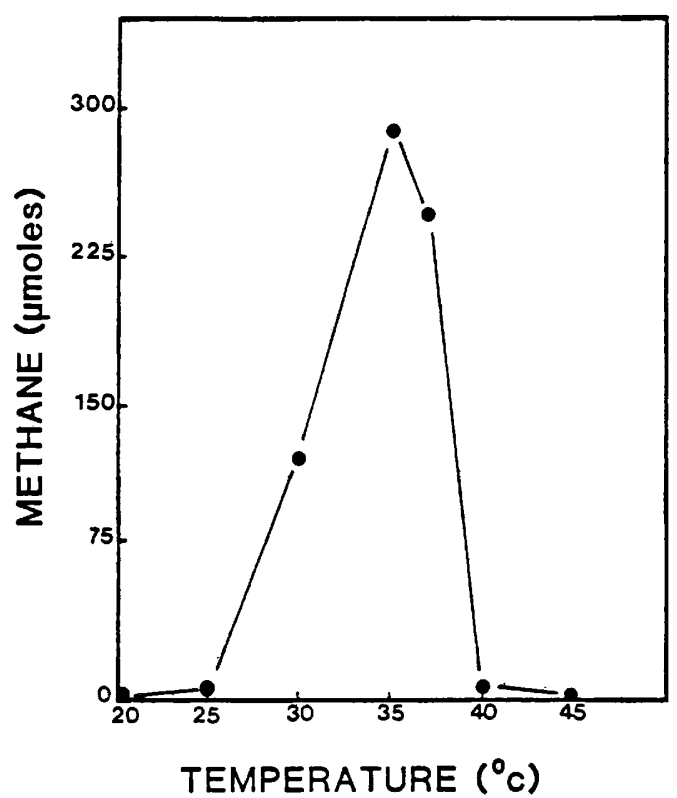

FIG. 4. Effect of temperature on methane production by Methanogenium aggregans. Cultures were grown in $20 \mathrm{ml}$ of liquid medium for 5 days at $37^{\circ} \mathrm{C}$.

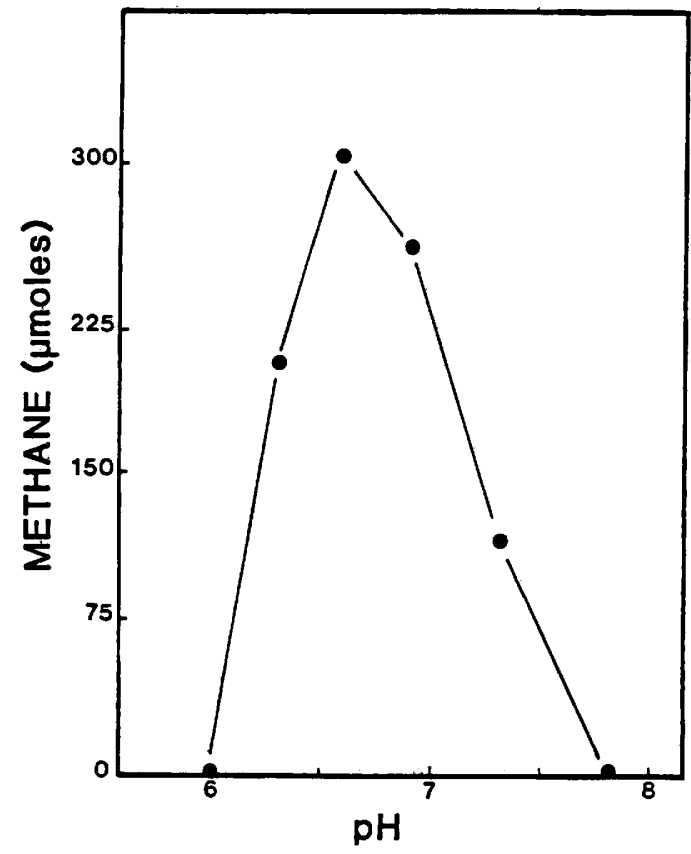

FIG. 5. Effect of $\mathrm{pH}$ on methane production by Methanogenium aggregans. Cultures were grown in $20 \mathrm{ml}$ of liquid medium for 7 days at $35^{\circ} \mathrm{C}$.

Methanogenium as well; "Methanogenium olentangyi" does not use formate, and Methanogenium thermophilicum (14) and the thermophilic Methanogenium of Ferguson and Mah (6) both exhibit thermophilic temperature optima.

We propose that our isolate be placed in the genus Methanogenium as a new species, Methanogenium aggregans sp. nov., with the species description given below.

Methanogenium aggregans sp. nov. (ag'gre.gans. L. part. aggregans adding to, aggregating, forming clumps) cells stain gram negative; irregular cocci occur singly or in aggregates and have an average diameter of $1 \mu \mathrm{m}$. Not motile; sensitive to $0.03 \%$ sodium dodecyl sulfate. $\mathrm{H}_{2}-\mathrm{CO}_{2}$ and formate are substrates for growth and methane production. Acetate, methanol, and methylamine are not metabolized. Acetate plus either yeast extract or Trypticase peptone is required for growth.

$\mathrm{NaCl}$ requirement, $<0.2 \%$.

The optimal growth temperature is $35^{\circ} \mathrm{C}$. The $\mathrm{pH}$ for optimum growth is between 6.5 and 7.0.

The guanine-plus-cytosine content is $52 \mathrm{~mol} \%$.

The type strain is strain MSt (= DSM 3027).

\section{ACKNOWLEDGMENTS}

We thank F. M. Bordeaux for performing the guanine-plus-cytosine determinations and David $\mathbf{R}$. Boone for perusing and reviewing the manuscript. We especially appreciate the immunological fingerprinting of our isolate by E. Conway de Macario.

This research was supported in part by research grant DE-AT0380ER10684 from the U.S. Department of Energy, by research grants 5080-323-0423 and FLA-2170 from the Gas Research Institute, Chicago, Ill., and by grant 82.21.091.3261 from the Agence Française pour la Maîtrise de l'Energie.

\section{LITERATURE CITED}

1. Bălch, W. E., G. E. Fox, R. J. Magrum, and R. S. Wolfe. 1979. Methanogens: reevaluation of a unique biological group. Microbiol. Rev. 43:260-296. 
2. Baresi, L., R. A. Mah, D. M. Ward, and I. J. Kaplan. 1978. Methanogenesis from acetate: enrichment studies. Appl. Enviroh. Microbiol. 36:186-197.

3. Conway de Macario, E., A. J. L. Macario, and M. J. Wolin. 1982. Antigenic analysis of Methanomicrobiales and Methanobrevibacter arboriphilus. J. Bacteriol. 152:762-764.

4. Conway de Macario, E., A. J. L. Macario, and M. J. Wolin. 1982. Specific antisera and immunological procedures for characterization of methanogenic bacteria. J. Bacteriol. 149:320-328.

5. Corder, R. E., L. A. Hook, J. M. Larkin, and J. I. Frea. 1983. Isolation and characterization of two new methane-producing cocci: Methanogenium olentangyi, sp. nov., and Methanococcus deltae, sp. nov. Arch. Microbiol. 134:28-32.

6. Ferguson, T. J., and R. A. Mah. 1983. Isolation and characterization of a $\mathrm{H}_{2}$-oxidizing thermophilic methanogen. Appl. Environ. Microbiol. 45:265-274.

7. Huber, H., M. Thomm, H. König, G. Thies, and K. O. Stetter. 1982. Methanococcus thermolithotrophicum, a novel thermophilic lithotrophic methanogen. Arch. Microbiol. 132:47-50

8. Hungate, R. E. 1969. A roll tube method for cultivation of strict anaerobes, p. 117-132. In J. R. Norris and D. W. Ribbons (ed.), Methods in microbiology, vol. 3B. Academic Press, Inc., New York.

9. Jones, W. J., J. A. Leigh, F. Maver, C. R. Woese, and R. S. Wolfe. 1983. Methanococcus jannaschii sp. nov., an extremely thermophilic methanogen from a submarine hydrothermal vent. Arch. Microbiol. 136:254-261.

10. Jones, W. J., M. J. B. Paynter, and R. Gupta. 1983. Characterization of Methanococcus maripaludis sp. nov., a new methanogen isolated from salt marsh sediments. Arch. Microbiol.
135:91-97

11. Preston, J. F., and D. R. Boone. 1973. Analytical determination of the buoyant density of DNA in acrylamide gels after preparative $\mathrm{CsCl}$ gradient centrifugation. FEBS Lett. 37:321-324.

12. Price, C. W., G. B. Fuson, and H. J. Phaff. 1978. Genome comparison in yeast systematics: delimitation of species within the genera Schwanniomyces, Saccharomyces, Debaryomyces, and Pichia. Microbiol. Rev. 42:161-193.

13. Rhodes, M. E. 1958. The cytology of Pseudomonas sp. as revealed by a silver-plating staining method. J. Gen. Microbiol. 18:639-648.

14. Rivard, C. J.; and P. H. Smith. 1982. Isolation and characterization of a thermophilic marine methanogenic bacterium, Meth anogenium thermophilicum sp. nov. Int. J. Syst. Bacteriol. 32:430-436.

15. Robinson, R. W., D. E. Akin, R. A. Nordstedt, M. V. Thomas, and H. C. Aldrich. 1984. Light and electron microscopic examinations of methane-producing biofilms from anaerobic fixedbed reactors. Appl. Environ. Microbiol. 48:127-136.

16. Romesser, J. A., R. S. Wolfe, F. Mayer, E. Spiess, and A. Walther-Maruruschat. 1979. Methanogenium, a new genus of marine methanogenic bacteria, and characterization of Methanogenium cariaci sp. nov. and Methanogenium marisnigri sp. nov. Arch. Microbiol. 121:147-153.

17. Schildkraut, C. L., J. Marmur, and P. Doty. 1962. Determination of the base composition of deoxyribonucleic acid from buoyant density in $\mathrm{CsCl}$. J. Mol. Biol. 4:430-433.

18. Stadtman, T. C., and H. A. Barker. 1951. Studies on the methane fermentation. X. A new formate-decomposing bacterium, Methanococcus vannielii. J. Bacteriol. 62:269-280. 